\title{
TOPOGRAPHIC-ANATOMIC PECULIARITIES OF THE THORACIC PART OF THE TRACHEA IN HUMAN FETUSES AGED 4-6 MONTHS
}

\section{Tatiana V. KHMARA ${ }^{1 凶}$, Igor I. ZAMORSKII ${ }^{1}$, Oleg F. MARCHUK ${ }^{1}$, Mariana A. RYZNYCHUK ${ }^{1}$, Leonid V. SHVYHAR ${ }^{1}$, Mariana I. KRYVCHANSKA ${ }^{1}$, Violeta G. KHOMENKO ${ }^{1}$}

${ }^{1}$ Higher State Educational Institution of Ukraine "Bukovinian State Medical University", Chernivtsi, Ukraine

\author{
Received 11 Apr 2019, Accepted 19 May 2019 \\ hitps://doi.org/10.31688/ABMU.2019.54.2.13
}

\begin{abstract}
Introduction. Rapid development of perinatal medicine has led to an increase in the number of fetal surgical interventions performed intrauterine, on the trachea and principal bronchi. Therefore, topographic and anatomical peculiarities of the trachea and its morphometric parameters in the human fetuses of different ages cause interest of morphologists and surgeons.
\end{abstract}

The objective of the study was to determine the skeleto-topic nature and the morphometric indices of the thoracic part of the trachea in the human fetuses aged 4-6 months.

Materials and methods. Anatomical study of typical and variant anatomy of the thoracic part of the trachea involved 37 specimens of human fetuses, of 81.0-230.0 $\mathrm{mm}$ of crown-rump length, by means of macro-microscopic preparation and morphometry.

Results. In the examined 4-6-month-old human fetuses, trachea within the superior mediastinum is predominantly placed in the median sagittal plane (25 cases, 67.6\%), or is slightly replaced to the right (9 observations, $24.3 \%$ ) or to the left ( 3 cases, $8.1 \%$ ) from the median sagittal plane. In the fetuses aged 4-6

\section{Résumé}

Particularités topographiques-anatomiques de la partie thoracique de la trachée chez des foetus humains à l'age de 4-6 mois

Introduction. Le développement rapide de la médecine périnatale a entrainé une augmentation du nombre d'interventions chirurgicales foetales pratiquées en intra-utérin, sur la trachée et les bronches principales. Par conséquent, les particularités topographiques et anatomiques de la trachée et ses paramètres morphométriques chez les fœetus humains de différents âges suscitent l'intérêt des morphologues et des chirurgiens.

L'objectif de l'étude était de déterminer la nature squelettique et les indices morphométriques de la partie thoracique de la trachée chez les foetus humains âgés de 4 à 6 mois.

Matériaux et méthodes. L'étude anatomique de l'anatomie typique et variante de la partie thoracique de la trachée a été réalisée sur 37 échantillons de foetus humains de 81,0 à 230,0 mm de la longueur crânio-caudale, présentant une préparation macromicroscopique et une morphométrie. 
months the bifurcation of the trachea into the principal bronchi, is usually skeleton-topically determined at the level of the body of the II thoracic vertebra, and the pulmonary trunk bifurcates into the pulmonary arteries at the level of the body of the III thoracic vertebra. An intensive increase in the length and external diameter of the trachea within the superior mediastinum is noted in the fetuses aged 4 and 6 months. During the $4^{\text {th }}-6^{\text {th }}$ month of intrauterine development, these morphometric indices of the thoracic part of the trachea are 1.6 times higher.

Keywords: trachea, skeletotopy, syntopy, principal bronchi, fetus.
Résultats. Chez les fœetus humains examinés âgés de 4 à 6 mois, la trachée du médiastin supérieur est principalement placée dans le plan sagittal médian (25 cas, 67,6\%) ou est légèrement remplacée à droite (9 observations, 24,3\%), ou à gauche (3 cas, $8,1 \%)$ du plan sagittal médian. Chez les foetus âgés de 4 à 6 mois, la bifurcation de la trachée dans les bronches principales est généralement déterminée de manière squelettique au niveau du corps de la IIe vertèbre thoracique et le tronc pulmonaire se bifurque dans les artères pulmonaires au niveau du corps de la IIIe vertèbre thoracique. Une augmentation intensive de la longueur et du diamètre externe de la trachée dans le médiastin supérieur est constatée chez les foetus âgés de 4 et 6 mois. Au cours du 4ème au 6ème mois du développement intra-utérin, ces indices morphométriques de la partie thoracique de la trachée sont 1,6 fois plus élevés.

Mots-clés: trachée, squelettotopie, syntopie, bronches principales, fotus.

A number of anomalies are hazardous to the life of new-borns and require immediate medical attention.

The prevalence of the respiratory tract birth defects is $0.2-1$ per 10,000 live births ${ }^{3}$. The most common abnormalities of the trachea are: tracheomalacia, congenital tracheal stenosis, tracheoesophageal fistula and laryngotracheal fissure ${ }^{4}$. Quite rarely, there is a complete absence (agenesis) of the trachea with the opening of the principal bronchi into the oesophagus, or the attachment of the principal bronchi to the interior region of the oesophagus with a complete absence of the trachea. Agenesis of the trachea is usually a fatal abnormality; it occurs with a frequency of 1 per 50,000 new-borns ${ }^{5-6}$. Tracheobronchomegaly or Mounier-Kuhn's syndrome is a congenital dilatation of the trachea or principal bronchi in children. The splitting or bifurcation of the proximal bronchi, additional segmental bronchi, additional lung or its superior lobe, tracheal trifurcation are described ${ }^{3}$.

Rapid development of perinatal medicine has led to an increase in the number of surgical interventions for the tracheobronchial tree via intrauterine $\mathrm{e}^{7-11}$. Surgeries on the respiratory tract are not performed in the fetuses up till the 24 weeks of pregnancy. Although in some experimental centres intrauterine surgical interventions are performed beginning from 18 weeks $^{12-13}$. Therefore, topographic and anatomical peculiarities of the trachea and its morphometric parameters in the human fetuses of different ages cause interest of morphologists and surgeons.

The active implementation of perinatal prophylaxis and treatment of birth defects requires modern 
approaches and methods of studying of intrauterine development. Therefore, we believe that the anatomical studies during the fetal period of human ontogenesis, the purpose of which is to develop anatomical basis for diagnostic and therapeutic methods for fetal pathology, are of special significance.

The research is a fragment of the planned comprehensive multidisciplinary theme of the Departments of Human Anatomy named after M.H. Turkevych and the Department of Anatomy, Topographic Anatomy and Operative Surgery of HSEI of Ukraine "Bukovinian State Medical University" "Peculiarities of Morphogenesis and Topography of Systems and Organs in the Pre- and Postnatal Periods of Human Ontogenesis", the state registration No. 0115 U002769.

The OBJective OF the STUdY was to determine the skeleton-topic nature and the morphometric indices of the thoracic part of the trachea in the human fetuses aged 4-6 months.

\section{Materials ANd methods}

Anatomical study of typical and variant anatomy of the thoracic part of the trachea involved 37 specimens of human fetuses of 81.0-230.0 $\mathrm{mm}$ of crown-rump length (CRL) by means of macro microscopic preparation and morphometry. The research deals with only those cases where the cause of death was not associated with pathology of the organs and neuro-vascular formations of the neck and thoracic cavity. The study was conducted on the specimens of fetuses from the collection of the museum of the Department of Human Anatomy named after M.H. Turkevych of HSEI of Ukraine "Bukovinian State Medical University". The study of certain specimens of fetuses weighing $500.0 \mathrm{~g}$ or more was performed in Chernivtsi Oblast Communal Medical Facility "Bureau of Morbid Anatomy" in accordance with the cooperation agreement.

One of the important issues of the study is the choice of an adequate method of fetus fixation. Specific intrauterine fetal position may lead to distortion of true skeletal syntopic relations of the trachea with adjacent organs and neuro-vascular formations of the neck and thoracic cavity. To avoid this, the fetuses were straight fixed to a plate and placed into a container with formalin in a hanging condition. Before immersion into a formalin solution, drip infusion was applied through the umbilical vein using $5 \%$ formalin solution. The fixation of the objects of the study was initially carried out in 5\% formalin solution during 7 days, and then during 30 days - in 10\% formalin solution. Before the beginning of the macroscopic examination of the trachea and the principal bronchi, anthropometric measurements and marking of human fetal specimens were performed.

For a more precise description of the skeleton-topic nature of the study objects, initially, the isolation and marking of the spinal processes of the six superior thoracic vertebrae were performed. The transverse dissection of the thorax was performed at the level or slightly higher $(2.0-5.0 \mathrm{~mm}$, depending on the age of the fetus) of the jugular incisura of the sternum and clavicles, and the longitudinal dissections of the thorax were made at the level of the anterior axillary lines. The region of the superior mediastinum is located above the conditional plane, which is drawn at the level of the superior edge of the roots of the lungs. The sternum, thymus and heart were removed to study the skeleton-topical nature of the bifurcation of the thoracic part of the trachea into the principal bronchi.

To make the horizontal sections the most informative, there were three levels determined: the upper limit of the superior mediastinum (the first thoracic vertebra), the middle part of the superior mediastinum (the level of tracheal bifurcation), the lower limit of the superior mediastinum (the superior edge of the roots of the lungs - the inferior edge of the fourth thoracic vertebra). Prior to the horizontal dissecting of the thoracic cavity, marking of the spinal processes of the five superior thoracic vertebrae was performed by sewing them with coloured polyamide threads. The analysis of horizontal sections at three levels made it possible to describe the exact skeletotopy of the thoracic part of the trachea in the fetal period of human ontogenesis.

The research was carried out in compliance with the essential bioethical provisions of the Council of Europe Convention on Human Rights and Biomedicine (dated April 04, 1997), the Helsinki Declaration of the World Medical Association on the Ethical Principles of Scientific Medical Research Involving Human Subjects (1964-2013), the Order of the Ministry of Health of Ukraine No. 690 dated September 23, 2009. The Commission on Biomedical Ethics of the HSEI of Ukraine "Bukovinian State Medical University" has not found any violations of moral and legal norms in the process of conducting a scientific study.

\section{Results AND DISCUSSION}

It was established that in early human fetal period (fetuses of 81.0-135.0 $\mathrm{mm}$ of CRL) the cervical part of the trachea passes into its thoracic part at the level of the jugular incisura of the sternum. At this level, the brachiocephalic trunk is tightly attached to the trachea. In the superior mediastinum the trachea is usually located in the median sagittal plane 
(8 cases) or is somewhat deviated to the right (fetuses of 85.0 and $95.0 \mathrm{~mm}$ of CRL) or to the left (fetuses of $110.0 \mathrm{~mm}$ of CRL).

Tracheal bifurcation into the principal bronchi occurs at the superior edge or in the middle of the body of the II thoracic vertebra in 10 out of $11 \mathrm{ex}$ amined fetuses aged 4 months. The splitting of the pulmonary trunk into the right and left pulmonary arteries is observed $1.4-2.3 \mathrm{~mm}$ below and to the left from the tracheal bifurcation.

In the fetus of $110.0 \mathrm{~mm}$ of CRL, the trachea is pressed back to the posterior and is slightly deviated to the left from the median sagittal plane. The length of the trachea within the superior mediastinum is 9.3 $\mathrm{mm}$, and its external diameter at the level of the II thoracic vertebra equals to $2.6 \mathrm{~mm}$. Tracheal bifurcation is at the level of the inferior edge of the II thoracic vertebra. The angle of the tracheal bifurcation constitutes $80^{\circ}$ (Fig. 1). The length of the right principal bronchus is $5.1 \mathrm{~mm}$, the diameter is $2.4 \mathrm{~mm}$; the length of the left principal bronchus equals to $7.2 \mathrm{~mm}$ and the diameter is $1.9 \mathrm{~mm}$. Splitting of the pulmonary trunk occurs $2.3 \mathrm{~mm}$ below and to the left from the tracheal bifurcation.

The length of the thoracic part of the trachea at the beginning of the fetal period of ontogenesis

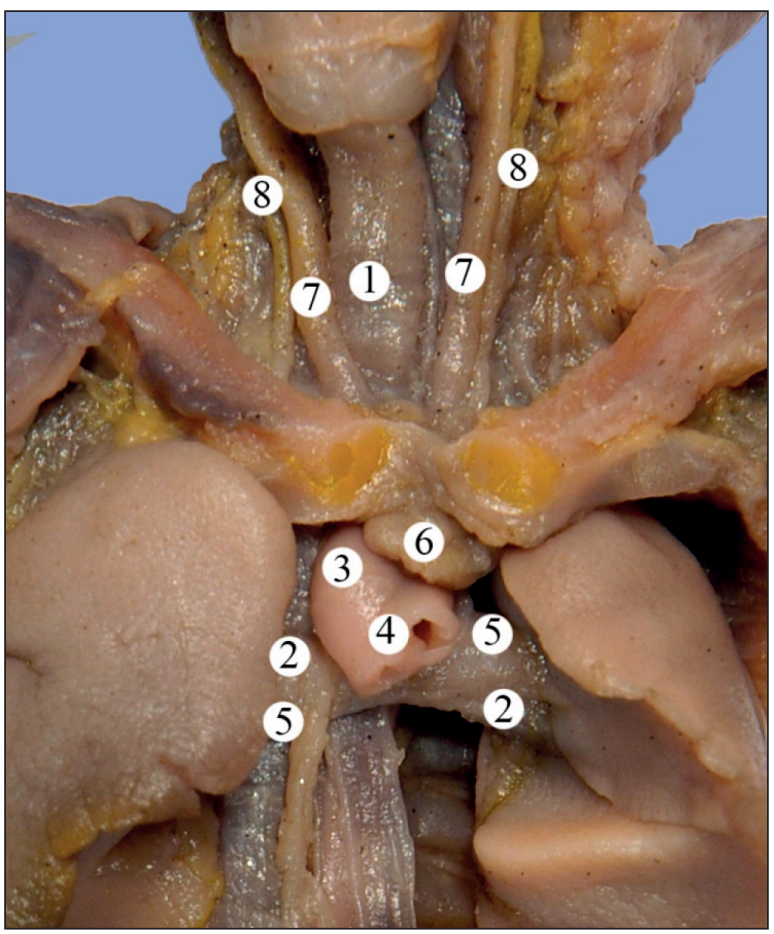

Fig. 1. Organs and structures of the superior mediastinum of the fetus of $110.0 \mathrm{~mm}$ of CRL. Macro specimen. Magnified 2.3 :

1 - trachea; 2 - principal bronchi; 3 - arch of the aorta; 4 - arterial duct; 5 - pulmonary arteries; 6 - thymus; 7 - common carotid arteries; 8 - vagus nerve. is $8.98 \pm 0.14 \mathrm{~mm}$, and the external diameter of the trachea (at the level of the II thoracic vertebra) is $2.28 \pm 0.08 \mathrm{~mm}$.

In 11 out of 12 examined 5-month-old fetuses, the tracheal bifurcation is skeleton-topically determined at the level of the superior edge or in the middle of the body of the II thoracic vertebra. In the fetus of $152.0 \mathrm{~mm}$ of CRL, the bifurcation of the trachea into the principal bronchi appears at the level of the superior edge of the body of the III thoracic vertebra.

The trachea is slightly replaced to the right in the fetus of $150.0 \mathrm{~mm}$ of CRL. The thoracic part of the oesophagus in the superior mediastinum is shifted to the left. The tracheal bifurcation into the principal bronchi in this fetus, as in most of the examined fetuses aged 5 months, occurs at the level of the superior edge of the body of the II thoracic vertebra. The arch of the aorta adjoins the left principal bronchus and the left lateral surface of the oesophagus (at the level of the body of the III thoracic vertebra). The left

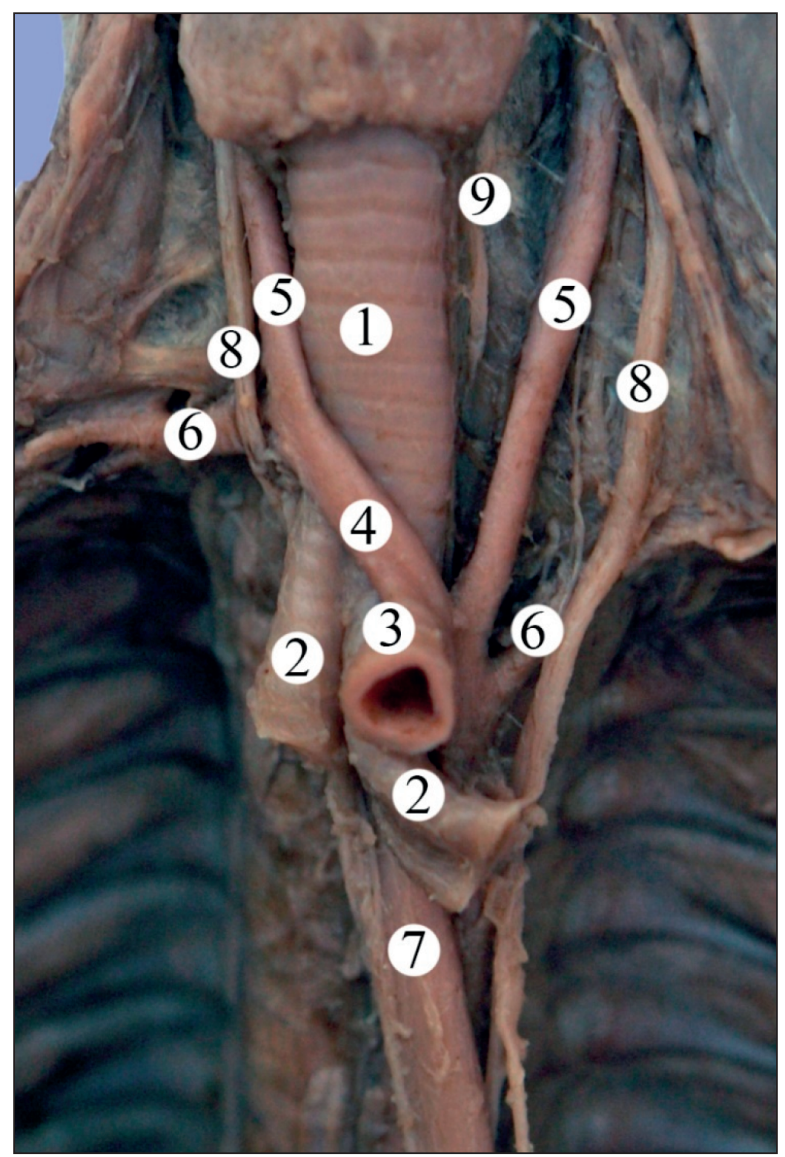

Fig. 2. Organs and structures of the superior mediastinum of the fetus of $150.0 \mathrm{~mm}$ of CRL. Macro specimen. Magnified 2.4x:

1 - trachea; 2 - principal bronchi; 3 - arch of the aorta; 4 - brachiocephalic trunk;"5 - common carotid arteries; 6 - subclavian arteries; 7 - oesophagus; 8 - vagus nerves; 9 - left recurrent laryngeal nerve. 
principal bronchus adjoins the anterior surface of the oesophagus just before the arch of the aorta (Fig. 2). The brachiocephalic trunk is tightly adjacent to the anterior surface of the tracheal bifurcation, and at the level of the right clavicle it divides into the right common carotid and subclavian arteries. The right vagus nerve in the superior mediastinum adjoins the lateral surface of the trachea. Somewhat higher the tracheal bifurcation it gives off two thin branches that pass along the anterior surface of the trachea and the right principal bronchus and further to the hilus of the right lung. The left vagus nerve in the superior mediastinum is located anteriorly and laterally to the left subclavian artery. The left vagus nerve at the

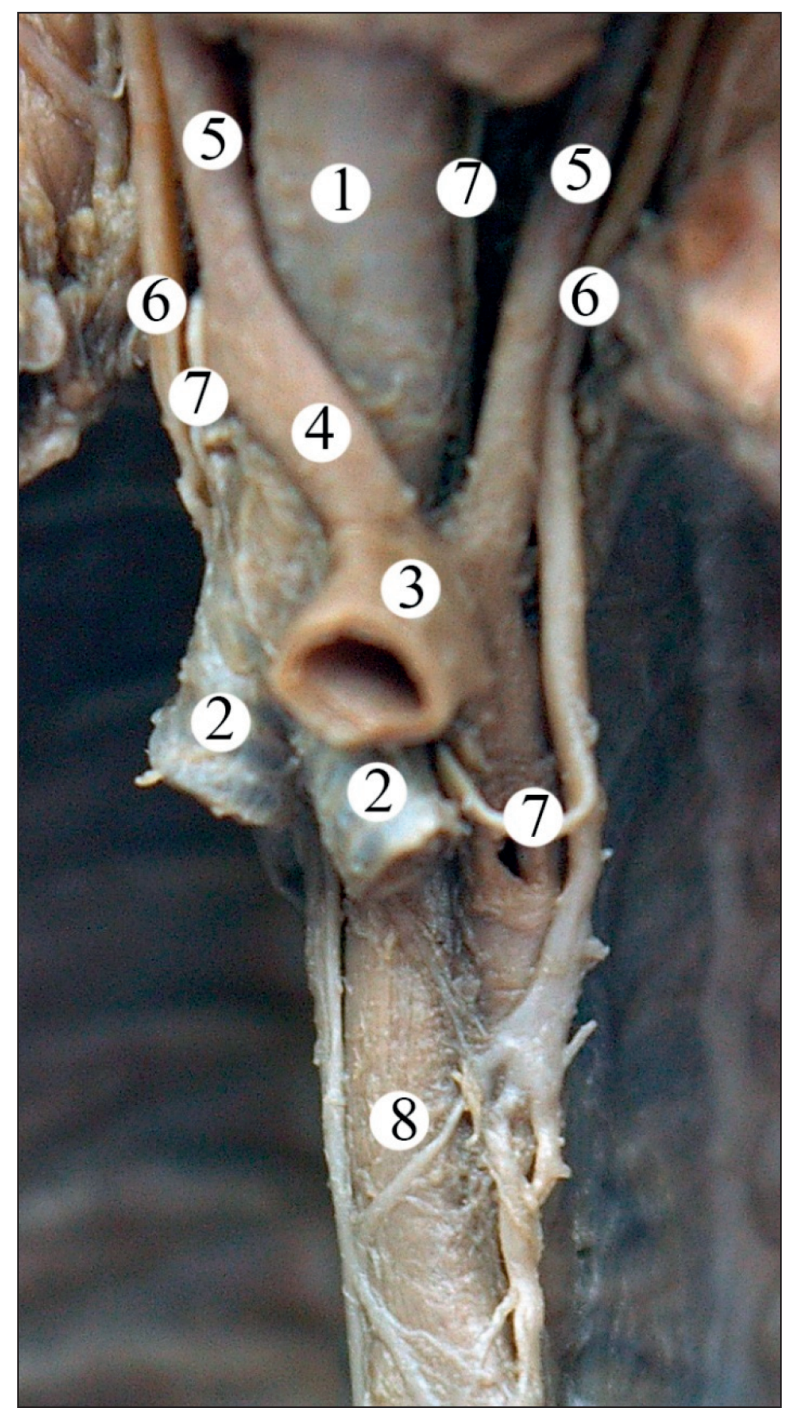

Fig. 3. Organs and structures of the superior mediastinum of the fetus of $180.0 \mathrm{~mm}$ of CRL.

Macro specimen. Magnified 2.5x:

1 - trachea; 2 - principal bronchi; 3 - arch of the aorta;

4 - brachiocephalic trunk; 5 - common carotid arteries; 6 - vagus nerves; 7 - recurrent laryngeal nerves; 8 - oesophagus. point of transition of the aortic arch in the thoracic part gives off the left recurrent laryngeal nerve, which circumflexes the arch of the aorta inferiorly, passes upwards along the lateral surface of the trachea, and then passes along the tracheoesophageal sulcus.

The length of the trachea in the superior mediastinum in the fetus of $180.0 \mathrm{~mm}$ of CRL is 11.0 $\mathrm{mm}$. The bifurcation of the trachea into the principal bronchi is skeleton-topically determined at the level of the middle of the body of the II thoracic vertebra. The right recurrent laryngeal nerve adjoins the lateral surface of the trachea. The arch of the aorta, $7.0 \mathrm{~mm}$ in length, passes obliquely from the front to the back and to the left, circumflexing superiorly the left principal bronchus. The right vagus nerve in the superior mediastinum adjoins the lateral surface of the trachea. Slightly higher the tracheal bifurcation 2 thin branches arise from the right vagus nerve, passing along the anterior surface of the trachea and the right principal bronchus, and further go to the hilus of the right lung. At the level of the hilus of the lung 3 branches arise from the vagus nerve to the anterior and lateral surfaces of the oesophagus. In the place of attachment to the left surface of the arch of the aorta, the left vagus nerve gives off the left recurrent laryngeal nerve, which circumflexes the aortal arch inferiorly, going upwards to the lateral surface of the trachea, and then passes along the tracheoesophageal sulcus (Fig. 3). At the level of the thoracic part of the aorta, numerous tracheal and oesophageal branches arise from the vagus nerve.

In 5-month-old fetuses, the thoracic part of the trachea, as a rule, occupies a median position, rarely shifted to the right (fetuses of 175.0 and $180.0 \mathrm{~mm}$ of CRL), or to the left (fetus of $185.0 \mathrm{~mm}$ of CRL) from the median sagittal plane. The length of the thoracic part of the trachea is $11.00 \pm 0.37 \mathrm{~mm}$, and the external diameter of the trachea (at the level of the II thoracic vertebra) is $3.12 \pm 0.09 \mathrm{~mm}$.

At this stage of development pulmonary trunk bifurcation into the right and left pulmonary arteries is determined at $2.5-3.0 \mathrm{~mm}$ below the tracheal splitting (the superior edge of the III thoracic vertebra) and 3.0-4.1 $\mathrm{mm}$ to the left of it.

In 12 fetuses aged 6 months, the tracheal bifurcation into the principal bronchi occurs skeleton-topically at the level of the middle of the body or the inferior edge of the II thoracic vertebra. In two cases, the skeleton-topic level of the tracheal bifurcation was different, in particular in the fetus of $225.0 \mathrm{~mm}$ of CRL - the superior edge of the body of the III thoracic vertebra, in the fetus of $230.0 \mathrm{~mm}$ of CRL - at the level of the superior edge of the body of the IV thoracic vertebra. In the fetus of $230.0 \mathrm{~mm}$ of CRL, 


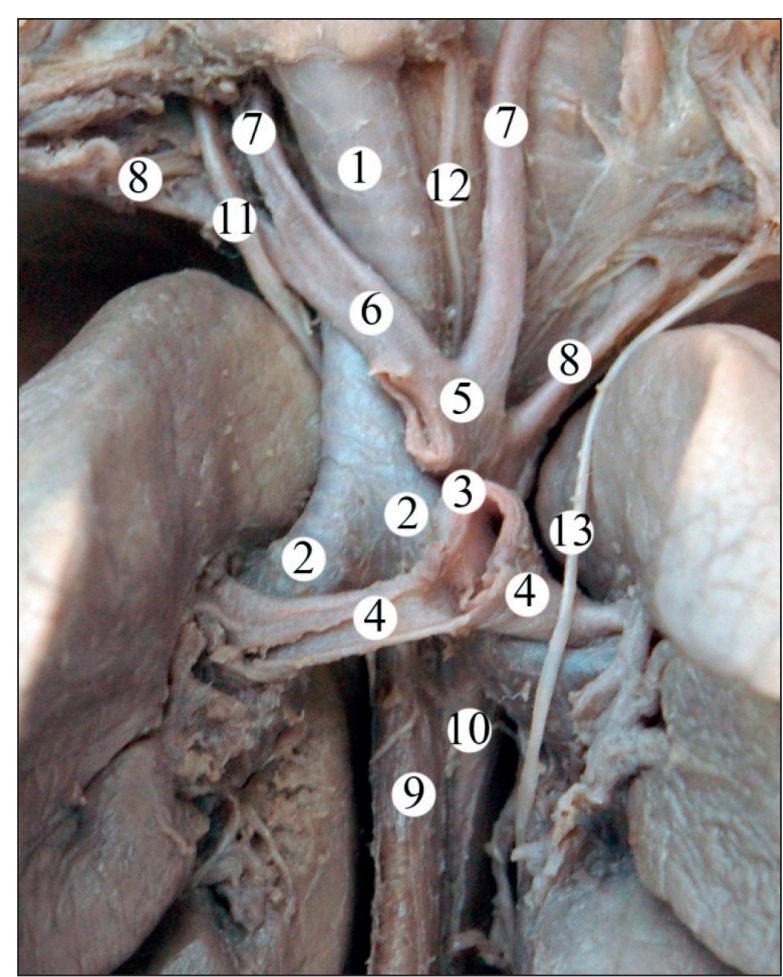

Fig. 4. Organs and structures of the superior mediastinum of the fetus of $230.0 \mathrm{~mm}$ of CRL. Macro specimen. Magnified 2.6

1 - trachea; 2 - principal bronchi; 3 - pulmonary trunk; 4 - pulmonary arteries; 5 - arch of the aorta;

6 - brachiocephalic trunk; 7 - common carotid arteries;

8 - subclavian arteries; 9 - oesophagus;

10 - descending aorta; 11 - right vagus nerve;

12 - left recurrent laryngeal nerve; 13 - left phrenic nerve. the bifurcation of the pulmonary trunk into the right and left pulmonary arteries occurs $3.0 \mathrm{~mm}$ below and $5.0 \mathrm{~mm}$ to the left from the splitting of the trachea (Fig. 4). The length of the right pulmonary artery is $10.5 \mathrm{~mm}$, the diameter is $4.5 \mathrm{~mm}$, of the left artery of the same name is $6.0 \mathrm{~mm}$ and $3.5 \mathrm{~mm}$ respectively. At the root of the right lung, the superior position is occupied by the principal bronchus, below which there is a pulmonary artery, and lower - the superior pulmonary vein, and then - the inferior pulmonary vein. At the root of the left lung, the cranial position is occupied by the pulmonary artery, below the artery there is the superior pulmonary vein, then the principal bronchus, and lower - the inferior pulmonary vein. The left phrenic nerve passes between the pericardium and the mediastinal part of the parietal pleura, at a distance of $5.2 \mathrm{~mm}$ from the root of the left lung. The right phrenic nerve passes along the superior vena cava more straightforwardly, and is placed at a distance of $4.0 \mathrm{~mm}$ from the root of the right lung.

In 6-month-old fetuses, the trachea within the superior mediastinum is usually placed in the median sagittal plane (9 observations) or shifted slightly to the right (fetuses of 190.0, 195.0, 210.0, and 230.0 $\mathrm{mm}$ of CRL) and tightly adjoins the anterior-lateral surface of the oesophagus, which, in turn, is placed somewhat to the left from the median sagittal plane. In particular, in the fetus of $210.0 \mathrm{~mm}$ of CRL the trachea is shifted to the right from the median

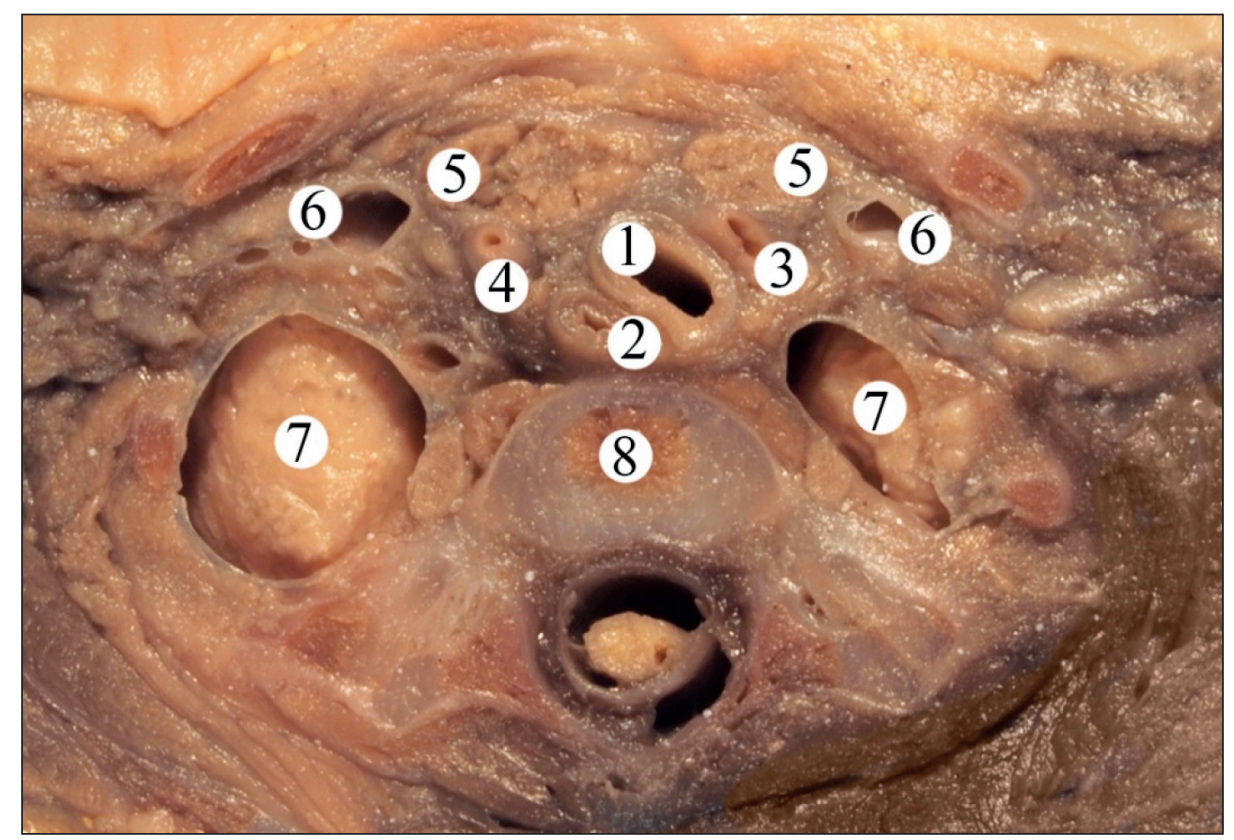

Fig. 5. Horizontal section of the fetus of $210.0 \mathrm{~mm}$ of CRL at the level of the II thoracic vertebra. Macro specimen. Magnified 2.6

1 - trachea; 2 - oesophagus; 3 - brachiocephalic trunk; 4 - left common carotid artery; 5 - lobes of the thymus; 6 - internal jugular veins; 7 - lungs; 8 - vertebra. 


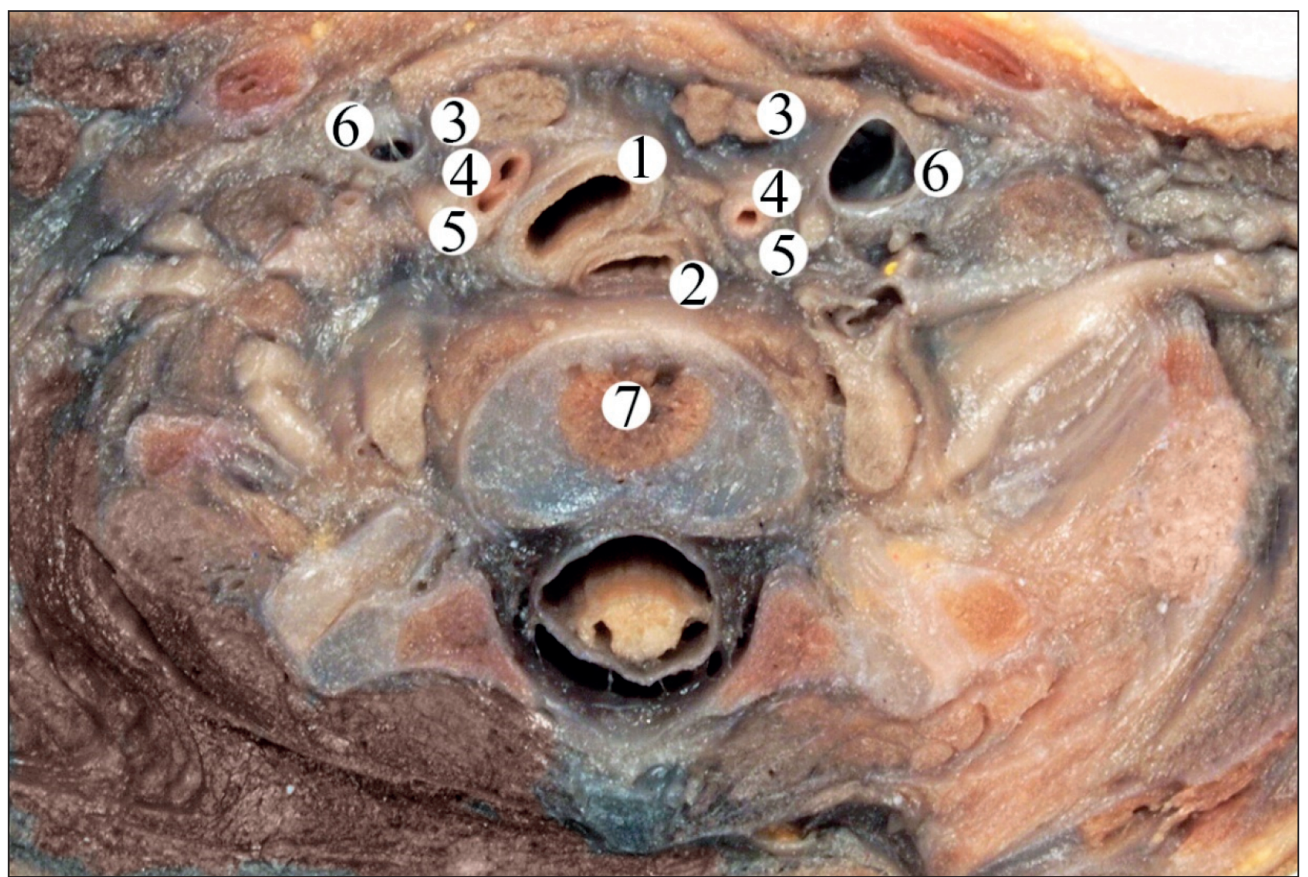

Fig. 6. Horizontal section of the fetus of $190.0 \mathrm{~mm}$ of CRL at the level of the I thoracic vertebra. Macro specimen. Magnified 2.4x:

1 -trachea; 2 - oesophagus; 3 - lobes of the thymus; 4 - common carotid arteries; 5 - vagus nerves; 6 - internal jugular veins; 7 - vertebra.

sagittal plane. The brachiocephalic trunk adjoins the anterior-lateral surface of the trachea (Fig. 5). The trachea is placed to the left from the median sagittal plane in one case (the fetus of $190.0 \mathrm{~mm}$ of CRL) (Fig. 6).

In fetuses aged 6 months, the bifurcation of the pulmonary trunk into the right and left pulmonary arteries is determined at 2.9-3.4 mm below the trachea splitting (the middle of the body or the inferior edge of the III thoracic vertebra) and 4.3-5.1 $\mathrm{mm}$ to the left of it. At this stage of development, the length of the thoracic part of the trachea is $14.00 \pm 0.53 \mathrm{~mm}$, and the external diameter of the trachea (at the level of the II thoracic vertebra) is $3.58 \pm 0.10 \mathrm{~mm}$.

\section{Conclusions}

In the examined human fetuses aged 4-6 months trachea within the superior mediastinum is predominantly placed in the median sagittal plane $(25$ cases, $67.6 \%$ ), or shifted slightly to the right (9 observations, $24.3 \%$ ) or to the left ( 3 cases, $8.1 \%$ ) from the median sagittal plane.

In 4-6-month-old fetuses the tracheal bifurcation into the principal bronchi is usually skeleton-topically determined at the level of the body of the II thoracic vertebra, and the splitting of the pulmonary trunk into the pulmonary arteries occurs at the level of the body of the III thoracic vertebra.
Intensive growth of the length and diameter of the trachea within the superior mediastinum is noted in the fetuses aged 4 and 6 months. During the $4^{\text {th }}-6^{\text {th }}$ month of intrauterine development, the given morphometric indices of the thoracic part of the trachea increase by 1.6 times.

The conducted research dealing with the anatomical variability of the thoracic part of the trachea in human fetuses aged 4-6 months confirms the need for further elucidation of its variant anatomy in 7-10-month-old fetuses.

\section{Compliance with Ethics Requirements:}

„The authors declare no conflict of interest regarding this article"

„The authors declare that all the procedures and experiments of this study respect the ethical standards in the Helsinki Declaration of 1975, as revised in 2008(5), as well as the national law."

"No funding for this study"

\section{References}

1. Pikalyuk VS, Osmanov AYu. Filo-, ontogenez organiv i sistem lyudini. Simferopol: Dolya, 2011;175 (in Ukranian).

2. Cao D, Zeng S, Li X, Zhou J, Zhou Q. Z scores of the fetal trachea and bronchial dimension. Prenat Diagn. 2019; 39(1):33-37. 
3. Windsor A, Clemmens C, Jacobs IN. Rare upper airway anomalies. Paediatr Respir Rev. 2016;17: 24-8.

4. Varela P, Torre M, Schweiger C, Nakamura H. Congenital tracheal malformations. Pediatric Surgery International. 2018; 34(7):701-713.

5. De Groot-van der Mooren MD, Haak MC, Lakeman P, et al. Tracheal agenesis: approach towards this severe diagnosis. Case report and review of the literature. Eur J Pediatr. 2012;171(3):425-431.

6. Mohammed H, West K, Bewick J, Wickstead M. Tracheal agenesis, a frightening scenario. J Laryngol Otol. 2016;130(3):314-7.

7. Szpinda M, Daroszewski M, Szpinda A, et al. New quantitative patterns of the growing trachea in human fetuses. Med Sci Monit 2012;18(6): PH63-70.

8. Fayoux P, Devisme L, Merrot O, Marciniak B. Determination of endotracheal tube size in a perinatal population: an anatomical and experimental study. Anesthesiology. 2006; 104:954-960
9. Harrison MR, Keller RL, Hawgood SB, et al. A randomized trial of fetal endoscopic tracheal occlusion for severe fetal congenital diaphragmatic hernia. N Engl J Med. 2003; 349:1916-24

10. Jani J, Gratacys E, Greenough A, et al. Percutaneous fetal endoscopic tracheal occlusion (FETO) for severe left-sided congenital diaphragmatic hernia. Clin Obstet Gynecol. 2005;48:910-922.

11. Kohl T, Hering R, Bauriedel G, et al. Fetoscopic and ultrasound-guided decompression of the fetal trachea in a human fetus with Fraser syndrome and congenital high airway obstruction syndrome (CHAOS) from laryngeal atresia. Ultrasound Obstet Gynecol. 2006; 27: 84-88.

12. Wagner W, Harrison MR. Fetal operations in the head and neck area: current state. Head Neck. 2002; 24: 482-490.

13. Wojcicki P, Drozdowski P. In utero surgery - current state of the art: Part I. Med Sci Monit. 2010;16(11): RA237-44. 